epigastric tenderness and pain in right side on movement. There was no cough; no expectoration. Negative results from auscultation and percussion. Improvement continued until the afternoon of June 30 , when the patient began to complain of dyspnoea and epigastric distress. $\mathrm{He}$ was seen again on the morning of July $\mathbf{I}$, when it was found that there had been a consolidation of the base of the left lung posteriorly. There was dulness over the region; bronchial breathing; crepitant râles. No cough or expectoration. Pulse IIO; temperature $100^{\circ}$; respiration 26. There was profuse sweating and extreme thirst. No trouble could be discovered in the right side. Heart sounds more normal. Pupil still dilated. On the 2 d, the left side was found to be clearing up, but examination of the right side revealed dulness over the lower twothirds posteriorly, together with bronchial breathing and crepitant râles. The temperature was normal ; pulse 120 , weak and lacking in volume. Heart sounds were normal but labored. Cough and expectoration were still absent. On the $3^{\mathrm{d}}$, percussion elicited dulness over the entire right lung with bronchial breathing, but no râles. The temperature was $98^{\circ}$; respiration 34 ; appetite was lost. There was great thirst, and the patient complained of being excessively hot when the extremities were cold to the touch. There was a slight hacking from time to time, as if clearing of the throat. The patient suffered no pain. The heart's action was labored. On the $4^{\text {th }}$ and $5^{\text {th }}$, the symptoms continued about the same, except perhaps more marked. There was a growing loss of power in the heart's action. Pulse 130, regular and weak; temperature $97.5^{\circ}$. On the 6 th, the radial pulse could with difficulty be detected. There was intense dyspnœa. The extremities became still more cold to the touch, though the patient could scarcely tolerate any covering over them. He complained of excessive warmth. Physical signs were the same, except the presence of a few moist râles at the base of the left lung. The apex beat seemed crowded about two inches and a half to the left. July 7 , an aspiration needle was introduced into the right side, but failed to discover any fluid. I saw the patient with Dr. Vander Laan on the afternoon of this day. He was evidently at that time in extremis. The extremities were cold and pulseless. He was cyanosed. Breathing was labored and shallow. The heart was weak; the second sound almost wholly lost. There seemed complete consolidation of the right lung with some congestion of the base of the left. The mind was clear, and had been from the first. There was still dilatation of the left pupil. The patient had scarcely slept since the accident. He died that evening. Unfortunately an autopsy was not allowed.

This case has seemed to me a particularly in- teresting one, and as having some bearing on the question of the local or constitutional nature of pneumonia, if it be a pneumonia, as its physical signs would seem to have it. Loomis, arguing for the constitutional nature of the disease, claims that a traumatism never produces a lobar pneumonia. It is to be regretted that a post-mortem examination could not be had in this case, but if physical signs alone can be relied on, we had here a pathological condition of the lung similar to that existing in that malady, and it seems to me a case in point of lobar pneumonia of traumatic origin, The nervous pneumonia observed throughout would seem to indicate that the force of the injury was spent upon the cerebro-spinal system. It is a well-known fact that hepatization of the lung may be produced by section of the vagus. Why may we not attribute the consolidation in this case to a lesion of the pneumogastric? If the engorgement was caused in this instance by a deranged vagus, why not in every case, the chill and fever depending entirely upon the extent to which the same causes influence the heat centre of the brain? Muskegon, Mich.

FRANK W. GaRbER, B.S., M.D.

\section{The Minnesota Medical Act.}

To the Editor:-In response to the suggestions of many of the profession, permit me to submit to your journal a brief résumé of the work accomplished by the State Board of Medical Examiners of Minnesota in the brief period of their existence, working under the provisions of the present State Medical Practice Act. These statistics are presented trusting they may direct the attention of the profession anew to the benefit to be derived by both the public and profession by efficient medical legislation, and trusting it may further stimulate the profession in securing, at the hands of the respective legislatures, now in session, such legislation as is required to protect both the public and profession. The present Act regulating the practice of medicine in Minnesota, became operative, July I, I887, and succeeded the old Act that had been in successful operation for a period of four and a-half years. The old Act was a verbatim copy of the present Illinois Act, excepting that the exemption clause was five years instead of ten, which is the period of exemption of the Illinois Act. Through the operations of the old Act the profession of the State had experienced some of the benefits of medical legislation, and was therefore disposed to aid and support the present Act in every way possible. The Minnesota Act has been inforced in a quiet, conscientious and determined manner by a board composed of the leading representative men of the profession of the State. The Act has received no mention by the medical press of the country, not- 
withstanding it is the best Act of any State and is as ably enforced as any of the various State Medical Acts. The present board have held seven quarterly meetings, at which eighty-six physicians have applied to be examined. Of this number six were refused admission to the class, not having taken three full courses of medical lectures of six months duration each. Of the eighty entering the various examinations fifty-one were licensed. Some of this number underwent several quarterly examinations before being successful. Twenty-nine were rejected, not possessing the knowledge of Medicine required by the board. Of those who passed, forty-nine are Regulars and two Homoeopaths. Of those failing to pass the examination, eighteen were Regulars, eight were Homcopathic, and only three were eclectic physicians. Those passing the examinations of the board were mostly graduates of McGill, Harvard, Chicago Medical, and the University of Michigan, Students who were graduates of the two-term schools and those having sessions of less than six months duration, are of course prohibited the privilege of practice in the State.

PERRY H. MiliLARD, M.D.

St. Paul, Minn.

\section{A Needle in the Heart.}

To the Editor:-Noticing the article in the last Journal, by Sara A. Kime, M.D., "The Migration of a Needle," calls to my mind a case that came under my own observation about twentyeight years ago, in the village of Warsaw, Western New York, where I was then practicing.

I was called to attend Mr. T., æt, 20 years, who for many weeks had been suffering severe pain in the region of the heart, attended with violent palpitation upon making any considerable exertion. Not a moment passed, unless he was asleep, that he was not tormented with an indescribably oppressed feeling about the chest. The pulse was somewhat accelerated and irregular. I had the clothing removed from the chest, so that I could make a thorough examination by inspection, as well as by auscultation and percussion, and while passing my hand over the heart to ascertain the force of its impulse, I felt a little hardened elevation. It was not visible when looking at the chest, but it could be readily felt with the finger, or the flat surface of the hand pressed gently upon it, and moved upwards and downwards.

With a bistoury I incised the skin directly over it, and with a pair of forceps removed an ordinary sewing needle an inch and a-half in length, All the unpleasant symptoms very soon subsided, and in a week or two my patient was quite as well as he had ever been.

From the location of the needle, and the attend- ing symptoms, I was quite sure it had, for a time, found a resting place in the very substance of the heart itself. 734 College Ave, Racine, Wis.

JOHN G. MEACHEM, M.D.

\section{BOOK NOTICES.}

A Clinical Atlas of Venereal and Skin Diseases, Including Diagnosis, Prognosis and TreatMen't, By Rober' W. TAylor, A.M., M.D., Surgeon to Charity Hospital, New York, etc., etc. Philadelphia: Lea Brothers \& Co. I888. In eight parts. Price per part $\$ 2.50$.

We have received the first four parts of this handsome work, which is published in a manner highly creditable to the well-known house of Lea Brothers \& Co. The lithographs are executed by the Sinclairs, and it is needless to say are in the highest style of the art. The paper is superb, and the typography is exquisite.

There is no formal preface and the author commences part I by plunging directly into his subject. The publishers, however, have supplied a detached "prefaratory note" in which they say:

"As no clinic, however large, can furnish the necessary materials, the entire literature of the subjects has been searched for its best illustrations, and selections made with proper permission of living authors. These have been completed by numerous reproductions from a collection of original paintings from life, gathered by the Author during many years of practice."

The well-known views of Dr. Taylor on venereal diseases are set forth on these stately pages in a pleasant and straightforward manner; but there is one blemish in the first parts that we would gladly pass over, except that our duty to our readers requires that book notices in these columns shall be impartial and accurate. This blemish is the frequent occurrence of such phrases as this, on page I67: "For further particulars as to the use of preparations of iodine, see Bumstead and Taylor, page 875 " - -and again on the same page, "For full particulars of the method of using inunctions see Bumstead and Taylor on veneral diseases, page 86r." These remarks seem to imply that the Atlas is intended as a companion to the work of Bumstead and Taylor, whereas, in fact it is intended to be, and really is, complete in itself.

The author of the atlas surely could not have intended to depreciate this later work, and we only regret that such a magnificent work should not contain all the author thinks the text requires to fully declare his meaning.

Dr. Taylor is extremely cautious in his prognoses, and his candor is commendable ; thus in speaking of the etiology of acne simplex, he says : "The pivotal questions are, what causes the inflammation that precedes the formation of the plug? 